\title{
SCIENTIFIC REP RTS OPEN Author Correction: Human Sexual Cycles are Driven by Culture and Match Collective Moods
}

\section{Ian B. Wood ${ }^{1}$, Pedro L. Varela ${ }^{2}$, Johan Bollen ${ }^{1,3}$, Luis M. Rocha $\mathbb{1}^{1,2}$ \& Joana Gonçalves-Sá ${ }^{2}$}

Correction to: Scientific Reports https://doi.org/10.1038/s41598-017-18262-5, published online 21 December 2017

In Figure 3, one of the countries is incorrectly coloured. The correct Figure 3 appears below as Figure 1.

The Acknowledgements section in this Article is incomplete.

"For this work, LMR and IBW were partially funded by the National Institutes of Health, National Library of Medicine Program, grant 01LM011945-01. JGS was partially supported by grant PTDC IVC ESCT 53372012 , from the Fundação para a Ciência e a Tecnologia (FCT), and by the Welcome DFRH WIIA 60 2011, co-funded by the FCT and the Marie Curie Actions. JB was partially supported by grants from the Defense Advanced Research Projects Agency (DARPA) - NGS2 program (\#D17AC00005) and the Economic Development Agency (EDA) ED17HDQ3120040. Twitter data collection was supported by NSF Award No. IIS-0811994. Google Trends10 and WorldBank data31 are publicly available. The authors also thank D. Rocha of Proposal Development Services at Indiana University for scientific editing and D. Junk for his work on data processing and collection. R. Correira, A. Gates, A. Kolchinsky, and other members of the CASCI group and CNetS at Indiana University and P. Almeida, M.M. Pita and other members of the S\&P group at Instituto Gulbenkian de Ciência for their comments and assistance with this work."

should read:

"For this work, LMR and IBW were partially funded by the National Institutes of Health, National Library of Medicine Program, grant 01LM011945-01. JGS was partially supported by grant PTDC IVC ESCT 5337 2012, from the Fundação para a Ciência e a Tecnologia (FCT), and by the Welcome DFRH WIIA 60 2011, co-funded by the FCT and the Marie Curie Actions. JB was partially supported by grants from the Defense Advanced Research Projects Agency (DARPA) - NGS2 program (\#D17AC00005) and the Economic Development Agency (EDA) ED17HDQ3120040. Twitter data collection was supported by NSF Award No. IIS-0811994. Google Trends10 and WorldBank data31 are publicly available. The authors also thank D. Rocha of Proposal Development Services at Indiana University for scientific editing and D. Junk for his work on data processing and collection. R. Correira, A. Gates, A. Kolchinsky, and other members of the CASCI group and CNetS at Indiana University and P. Almeida, M.M. Pita and other members of the S\&P group at Instituto Gulbenkian de Ciência for their comments and assistance with this work. The collaboration between JGS and LMR was partially supported by a Fulbright Commission fellowship to LMR." 


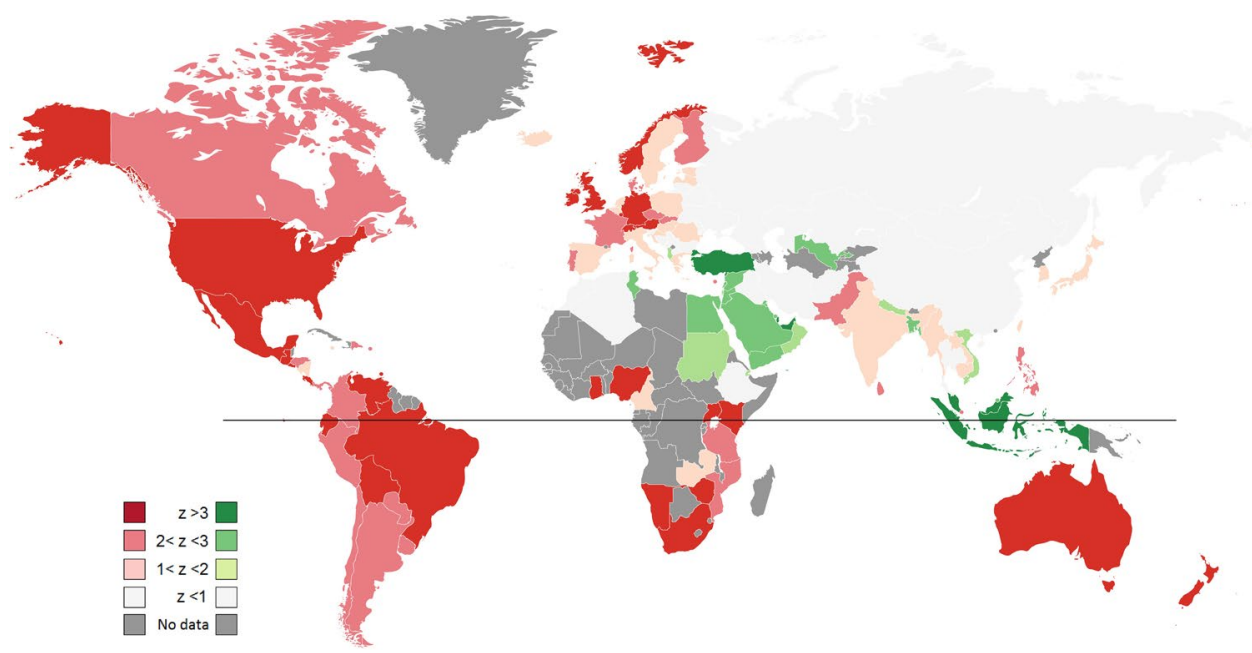

Figure 1. World-wide sex-search profiles. The world map is color-coded according to the z-score of each individual country's sex-search time-series. Shades of red represent a higher z-score (larger increase in searches) during Christmas week (on Christmas-centered data). Shades of green represent a higher z-score (larger increase in searches) during Eid-al-Fitr week (on Eid-al-Fitr centered data). Light grey denotes countries with no significant variation above mean in either of these weeks. Dark grey countries are those for which there is no GT data available. Black line represents the equator separating the hemispheres. Built using: https://mapchart.net/.

(i) Open Access This article is licensed under a Creative Commons Attribution 4.0 International License, which permits use, sharing, adaptation, distribution and reproduction in any medium or format, as long as you give appropriate credit to the original author(s) and the source, provide a link to the Creative Commons license, and indicate if changes were made. The images or other third party material in this article are included in the article's Creative Commons license, unless indicated otherwise in a credit line to the material. If material is not included in the article's Creative Commons license and your intended use is not permitted by statutory regulation or exceeds the permitted use, you will need to obtain permission directly from the copyright holder. To view a copy of this license, visit http://creativecommons.org/licenses/by/4.0/.

(C) The Author(s) 2018 